\title{
A study to determine important barriers in using managerial accounting
}

\author{
Rahmatollah Mohammadipour ${ }^{\mathrm{a}^{*}}$, Sohaila Mahdavi ${ }^{\mathrm{a}}$, Mohammad Hossein Bakhshandeh ${ }^{\mathrm{b}}$ and Farshad \\ Sabzalipour ${ }^{\mathrm{c}}$
}

${ }^{a}$ Department of Accounting, Ilam, Islamic Azad University of Ilam ,Iran

${ }^{b}$ Department of Accounting, Persian Gulf International Educational center, Iran

${ }^{c}$ Department of Accounting, Ilam university, Iran

\begin{tabular}{l}
\hline A R T I C L E I N F O \\
\hline Article history: \\
Received August 12, 2012 \\
Received in revised format \\
20 September 2012 \\
Accepted 1 October 2012 \\
Available online \\
October 2 2012 \\
\hline Keywords: \\
Cement industry \\
Managerial accounting \\
Efficiency \\
Profitability
\end{tabular}
A B S T R A C T

\begin{abstract}
Managerial accounting plays an important role for making prompt and efficient decisions to reduce troubles in the market. However, there are many circumstances where management team cannot make appropriate, fast and reliable managerial decisions. In this paper, we present a survey in cement industry and look to find out important factors as major barriers of managerial accounting implementation. The proposed model of this paper designs and distributes questionnaire among management teams who work for cement industry in Iran. The results of the survey indicate that lack of familiarity of managers with managerial accounting techniques, existence of unprofessional people in financial and accounting affairs and lack of having globally acceptable standards are major barriers in this industry for implementation of managerial accounting skills. However, our survey does not find any relationship between market turbulence and efficiency and implementation of managerial accounting skills.
\end{abstract}

(C) 2012 Growing Science Ltd. All rights reserved.

\section{Introduction}

Managerial accounting plays an important role for making prompt and efficient decisions to reduce troubles in the market. Managerial accounting normally helps people make fast managerial decisions about accepting new orders, making appropriate decisions for repair or replacement of equipments, removing the inefficient or unprofitable products, etc. (Atkinson et al., 2011). Managerial accounting also helps determine breakeven point and inventory management, choosing appropriate suppliers and, it is one of the most important requirements of business activities (Weygandt, 2009, Dittman et al., 2008). Budgeting accounting is another feature of business development and we may use managerial accounting skills to improve these systems. According to Kurunmäki (2008) accounting is a possess for making changes and the exercise and balance of power within organizations. Therefore, it is

\footnotetext{
* Corresponding author.

E-mail addresses: rm.accounting2@yahoo.com (R. Mohammadipour) 
possible to make use of managerial accounting through accounting information to have more efficient organizations.

Najafi and Ahmadkhani (2012) investigated the impacts of executing budgeting plan on governmental organizations. They designed a questionnaire consists of different questions and selected 94 people out of 125 financial managers who worked for various governmental organizations in province of Zanjan, Iran. The results of their studies indicated that the operational budgeting assists providing better performance measurement of governmental organizations, it is also a good tool for having more precise cost estimation, and it helps government allocate the requirement budget proportion to performance measurement. The results of their survey also indicated that operational budgeting redirect costs towards our objectives and make the overall budgeting crystal clear.

Pirayesh et al. (2012) investigated the effect of information technology, hiring high quality skilled management team, using high quality standards and increasing employees' awareness on managing internal control. The survey implemented a questionnaire based on Likert scale and distributed among the people who work in either administration or financial sectors of governmental agencies in province of Zanjan, Iran. The results of their investigation revealed that the use of information technology positively impacts management team to control their system, more effectively, using more skilled and specialized managers positively affects management internal control, an organization with suitable standard positively impacts management internal control and it could increase employees' awareness positively on management internal control.

Khodaei Valahzaghard and Salehi (2012) studied corporate governance and ownership impact on earning quality in Iranian private banks. The study implemented the information of 12 private banks over the period of 2005- 2010 using regression analysis based on panel data. Among various factors, the impact of big five shareholder were considered to be significant and positive on earning quality. Besides, the impact of one variable regression test disclosed that institutional ownership had positive influence on earning quality. However, the effects of other variables including percentage of ownership concentration, the size of board of directors, reliance on debt, logarithm of sum of assets, return of assets, logarithm of operating cash flow on earning quality were not significant. They concluded that institutional ownership had an important impact on earning quality simply since institutions normally had the access on professionals to control management.

In this paper, we try to understand which factors are preventing management teams of cement industry from using managerial accounting advantages. The organization of this paper first presents details of the proposed model in section 2 and section 3 presents the findings of our survey. Finally, concluding remarks are given in the last section of the paper.

\section{The proposed model}

The proposed model of this paper designs and distributes among twelve experts. Cronbach alpha has been calculated as 0.8968 , which is well above 0.70 and this validates the questionnaire. There are five hypotheses associated with the proposed model of this paper as follows,

1. The lack of familiarity of managers with managerial accounting techniques prevents them to use these techniques in cement industry.

2. The existence of unprofessional people in financial and accounting affairs prevents managers to implement managerial accounting techniques.

3. Governmental ownership, monopolized industry and lack of competition are major barriers in developing managerial accounting systems.

4. The lack of having globally acceptable standards is the major barriers of using managerial accounting systems.

5. Rapid changes in economical policies are major barriers for having good managerial accounting in this industry. 
Statistical population of this survey includes 59 active cement firms, where 30 of them have been listed in Tehran Stock Exchange and we have considered all of them for to examine the hypotheses of this survey.

In our survey, most participants were middle age and according to our survey, $29.1 \%$ were between 31 to 40 years old, $54 \%$ were 41 to 50 years old. In terms of educational level, they were highly educated since 93\% maintained bachelor degree of science or higher degrees. In terms of areas of education, $29.9 \%$ of the participants finished their education in management field, $9.2 \%$ studied economics, $6.9 \%$ were enrolled in accounting, $6.9 \%$ had a degree in law and $47.1 \%$ were involved in other sciences. Fig. 1 shows details of the job experiences for the people who participated in our survey.

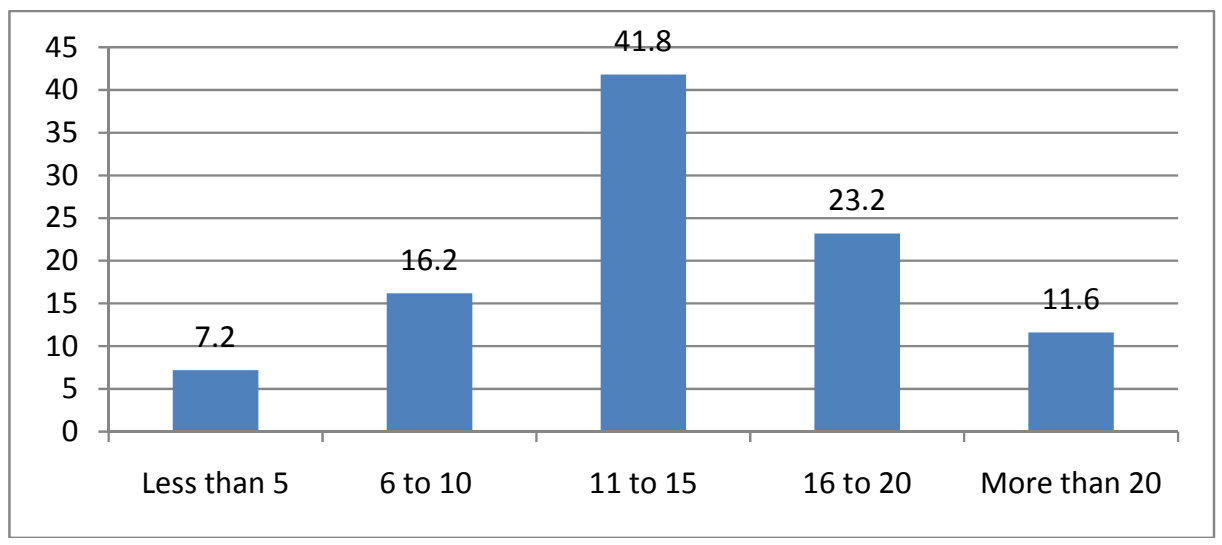

Fig. 1. Frequencies of educational background among management team members

In terms of years of experiences, only $7.2 \%$ of the participants had less than 5 years of job experience, $16.2 \%$ of the participants maintained 6 to 10 years of job experience, $41.8 \%$ of the people who took part in our survey had 11 to 15 years of job experiences, 23.2\% maintained between 16 to 20 years of job experience and the remaining $11.6 \%$ had more than 21 years of job experience. Fig. 1 shows participants' job experience.

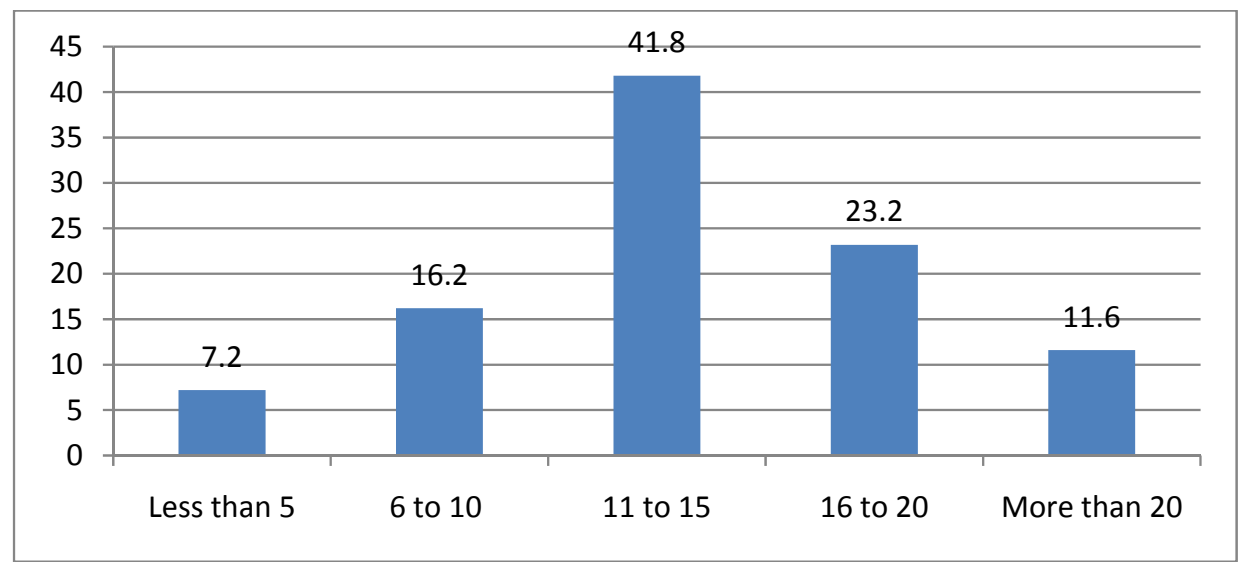

Fig. 2. Frequencies of job experiences among management team members

All questions of the survey have been designed in Likert scale and to test the hypotheses of this research work, we use binomial method where the first three categories, very low, low and average, are considered for the first group and the second category, high and very high, contains two other 
options. Therefore, the likelihood of rejecting a hypothesis is 0.6 and a hypothesis is accepted with the possibility of 0.4 .

\section{The results}

In this section, we present details of our findings for testing various hypotheses.

\subsection{First hypothesis: familiarity of management team with managerial accounting}

There is no doubt that when the management team does not know much about the advantage of using managerial accounting they may not be able to contribute to their system, effectively. In our study, the $\mathrm{z}$-value is calculated as follows,

$Z=\frac{x-\mu_{x}}{\delta_{x}}=\frac{x-n p}{\sqrt{n p q}}=\frac{36-43(.0 .4)}{\sqrt{43 \times 0.4 \times 0.6}}=5.85$.

As we can observe from the results of Eq. (1), $Z=5.85$, which is well above the critical value of $Z_{0.05}=1.645$ and we can reject the null hypothesis and we can conclude that management teams are not familiar with managerial accounting issues well enough to contribute to their organization.

\subsection{Second hypothesis: Lack of having skilled management team and managerial accounting}

As we explained earlier, human resources are the most important parts of organizations and when they maintain high level of skills, they can make some big changes using managerial accounting techniques. In our study, the z-value is calculated as follows,

$Z=\frac{x-\mu_{x}}{\delta_{x}}=\frac{x-n p}{\sqrt{n p q}}=\frac{41-43(.0 .4)}{\sqrt{43 \times 0.4 \times 0.6}}=7.41$.

As we can observe from the results of Eq. (1), $Z=7.85$, which is well above the critical value of $Z_{0.05}=1.645$ and we can reject the null hypothesis and conclude that management teams are not highly skilled and they are not familiar with managerial accounting issues well enough to contribute to their organization.

\subsection{Third hypothesis: Government ownership and market monopoly}

As we explained earlier, when there is a high level of concentration in business and government controls most of the industry, it is not possible to make agile changes using managerial accounting techniques. Market monopoly always creates challenges for productivity since management team is unwilling to make changes and restructure business model using managerial accounting skills. In our study, the z-value is calculated as follows,

$Z=\frac{x-\mu_{x}}{\delta_{x}}=\frac{x-n p}{\sqrt{n p q}}=\frac{32-42(.0 .4)}{\sqrt{42 \times 0.4 \times 0.6}}=4.79$.

As we can observe from the results of Eq. (1), $Z=4.79$, which is well above the critical value of $Z_{0.05}=1.645$ and we can reject the null hypothesis and conclude that governmental ownership has 
created much trouble for this industry and it can be considered as a major barrier for development of this industry using managerial accounting skills.

\subsection{Fourth hypothesis: Lack of having good standards}

In our survey, lack of having good standards could be a possible barrier for having efficient units and the study yields the following results for our survey,

$$
Z=\frac{x-\mu_{x}}{\delta_{x}}=\frac{x-n p}{\sqrt{n p q}}=\frac{38-43(.0 .4)}{\sqrt{43 \times 0.4 \times 0.6}}=6.48 .
$$

As we can observe from the results of Eq. (1), $Z=4.79$, which is well above the critical value of $Z_{0.05}=1.645$ and we can reject the null hypothesis and conclude that lack of having good standards has created much trouble for this industry and it can be considered as a major barrier for development of this industry using managerial accounting skills.

\subsection{Fifth hypothesis: Market turbulence}

Market turbulence and rapid economic change are other important factors blaming this industry. In fact, any instability in economy normally creates inefficient units in any sector of industry. In our study, the z-value is calculated as follows,

$$
Z=\frac{x-\mu_{x}}{\delta_{x}}=\frac{x-n p}{\sqrt{n p q}}=\frac{17-39(.0 .4)}{\sqrt{39 \times 0.4 \times 0.6}}=0.46
$$

As we can observe from the results of Eq. (1), $\mathrm{Z}=0.46$. Therefore, we cannot reject the null hypothesis and conclude that any turbulence in the market could be known as a major barrier for using managerial accounting skills.

\section{Conclusion}

In this paper, we have presented an empirical study to find important factors influencing implementation of managerial accounting techniques and ideas to improve the performance of a system. The proposed model of this paper has been applied in cement industry in Iran and by considering five hypotheses. Based on the results of our survey, we have concluded that economical instability was not an important barrier for the implementation of managerial accounting. However, the other factors including lack of familiarity of managers with managerial accounting techniques, existence of unprofessional people in financial and accounting affairs and lack of having globally acceptable standards were major barriers in this industry for implementation of managerial accounting skills.

\section{Acknowledgment}

The authors would like to thank all dedicated people in Cement industry who cordially participated in this survey. We are also grateful to constructive comments on earlier version of this paper. 


\section{References}

Atkinson, A. A., Kaplan, R. S., Matsumura, E. M., \& Young, S.M. (2011). Management Accounting: Information for Decision Making and Strategy Execution. $6^{\text {th }}$ ed. Pearson Education, Inc.

Dittman, D.A., Hesford, J.W., \& Potter, G. (2008). Managerial Accounting in the Hospitality Industry. Handbooks of Management Accounting Research, 3, 1353-1369.

Khodaei Valahzaghard, M., \& Salehi, A. (2012). Investigating the effective factors on management internal controls applying. Management Science Letters, 2, 2607-2614.

Kurunmäki, L. (2008). Management accounting, economic reasoning and the new public management reforms. Handbooks of Management Accounting Research, 3, 1371-1383.

Pirayesh, R., Niazi, R., \& Ahmadkhani, A. (2012). Investigating the effective factors on management internal controls applying. Management Science Letters, 2, 1203-1208.

Najafi, M., \& Ahmadkhani, A. (2012). The advantage of using operational budgeting on governmental organization. Management Science Letters, 2, 101-106.

Weygandt, J.J., Kimmel, P.D., \& Kieso, D. E. (2009). Managerial Accounting: Tools for Business Decision Making. Wiley. 